\title{
Chronicle of the Journal Munibe Antropologia-Arkeologia 2017
}

In 2017, the journal Munibe Antropologia-Arkeologia reached 69 years of age, the last ten of which have taken place following the major change in its editorial team in 2007. The challenges set by the new digital formats and channels of knowledge have allowed Munibe to gradually consolidate as an important point of reference in the fields of prehistory, archaeology and anthropology in the Iberian Peninsula, together with increasing world-wide visibility. Year after year, we try to add new aspects and update the journal's format and contents so that it may become interesting and attractive for a growing number of authors on a wider international scale. The main new feature of this issue is the referencing system (HARVARD system, adapted to the requirements of the ELSEVIER network of journals), which is comparable with the systems used by other journals in our field of knowledge and which allows the use of most referencing applications almost automatically. Additionally, the journal has been restyled and its Editorial Committee has been enlarged considerably.

Twenty original manuscripts were submitted to the journal in the course of 2017, which were added to four that finally remained unpublished in the 2016 paper edition. Due to similar circumstances, the last two originals to be submitted could not be reviewed in time, and will be assessed in 2018. Therefore, a total of 22 manuscripts were considered for this paper edition. Each original was assessed by at least two external reviewers, and in some cases by three. Four papers were rejected for diverse reasons. The other eighteen, published in this issue, can be divided into those that needed a profound revision and the ones for which minor changes sufficed. The average time between receiving the acknowledgement of receipt signed by the corresponding author and the final decision whether to publish the paper or not was 31 weeks, although this varied greatly depending on several factors, such as the length and topic of the paper.

The reviewing system was again the double blind method, in which neither the authors know the identity of the reviewers nor these know who wrote the manus- cripts they are assessing. This meant that each manuscript had to be edited to remove any indication of the author(s) to the reviewers: references to the authors, citations in the text (replaced by the text "self-citation", to avoid breaking the thread of the argument), acknowledgements and bibliography cited. All the agents (guest editors, external reviewers and authors) were fully informed in writing about the reviewing mechanisms that would be applied and were given precise instructions for each step in the process, including a template to guide the reviewers' reports. As far as possible, communications between all the agents has been carried out electronically, and each author signed an acknowledgement of receipt for their manuscript, with the date given at the head of each paper, accepting the protocol described above.

The addition of DOI codes to the papers is improving their visibility in Internet substantially, as can be seen in the records monitoring them in Google Scholar. Since 1990 until the time this report was written (29 December 2017), the papers published in Munibe Antropologia-Arkeologia since 1983 have been cited 4,018 times (compared with 3,554 times, up to last year). 1,840 of these citations have been made since $2012(1,702$ up to last year). The papers published in the period 20122016 (89 papers) have already been cited 1,671 times, which provides an impact factor for the journal in the last five years of 1.81 citations per published paper. Any author can verify in this application the number of times that their paper has been referenced and the context of the citation. In the same period, the most often cited paper (16 times) was published in 2012 by Ana C. Pinto-LIona, Geoffrey Clark, Panagiotis Karkanas, Bonnie Blackwell, Anne R. Skinner, Peter Andrews, Kaye Reed, Alexandra Miller, Rosario Macías-Rosado and Jarno Vakiparta, "The Sopeña rockshelter, a new site in Asturias (Spain) bearing evidence on the Middle and Early Upper Palaeolithic in Northern Iberia".

\section{Alvaro Arrizabalaga. Chief Editor}

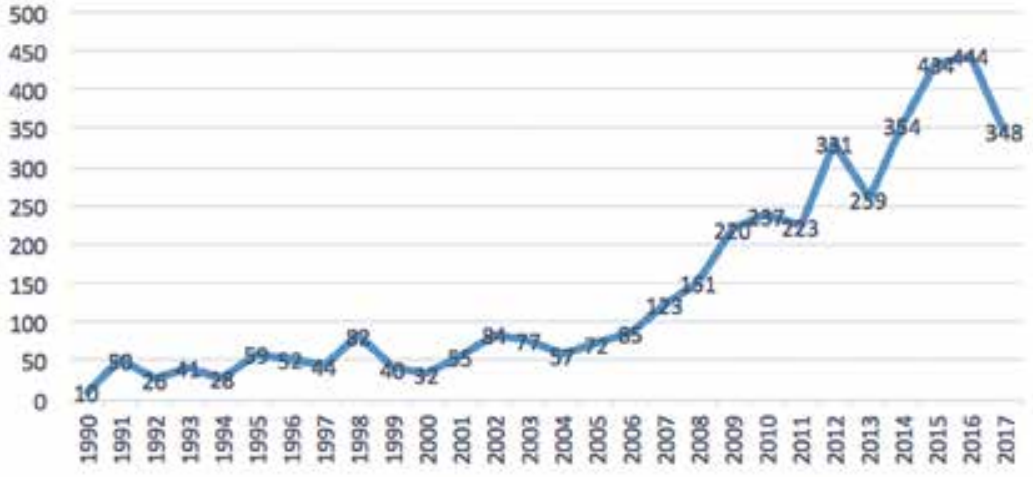

Citations to the Munibe AA journal in different academic media per year. 


\section{Munibe Antropologia-Arkeologia 2017 aldizkariaren kronika}

2017 honetan, Munibe Antropologia-Arkeologia aldizkariak 69 urte bete ditu, azkeneko hamarrak 2007an argitalpen-taldean egindako aldaketa handiaren ostean. Munibek jakintzaren formatu eta euskarri digital berrien aldeko apustua egin du, eta, horri esker, lehen lekuetan finkatu da penintsulako Historiaurrearen, Arkeologiaren eta Antropologiaren esparruetan, eta nazioartean ere gero eta ezagunagoa da. Urtez urte, berritasunak sartzen eta aldizkariaren formatua eta edukiak eguneratzea saiatzen gara, interesgarriagoa eta erakargarriagoa izan dadin gero eta egile gehiagorentzat, eta nazioarteko esparru zabalago batean. Idazkera bibliografiko berria da ale honek dakarren berritasun nagusia (HARVARD sistema, ELSEVIER aldizkari-sarearen eskakizunetara egokitutakoa). Izan ere, sistema hori bateragarriagoa da gure jakintza-esparruko beste aldizkari batzuek erabiltzen dutenekin, eta, beraz, ohiko erreferentzia-aplikazioak erabil daitezke modu ia automatikoan. Gainera, Argitalpen Batzordea modu nabarmenean berritu eta zabaldu du aldizkariak.

2017. urtean, jatorrizko 20 lan aurkeztu dira aldizkariaren erredakzioan aztertzeko, 2016ko paperezko edizioan argitaratu ezin izan ziren beste laurei batu zaizkienak. Antzeko egoerengatik, azkeneko bi jatorrizko lanak ezin izan dira ebaluatu oraindik, eta 2018an aztertuko dira. Hortaz, paperean atera den ale honetarako, 22 eskuidatzi aztertu dira. Jatorrizko lan bakoitzari bi kanpo-azterketa egin zaizkio gutxienez, eta hirugarren iritzi bat ere gehitu zaie batzuetan. Lan horietako lau baztertu egin dira, zenbait arrazoi zirela medio. Ale honetan argitaratu diren gainerako hemezortzietatik, erdiek aldaketa handiak behar izan dituzte, eta gainerakoek, berriz, nahikoa izan dute aldaketa txiki batzuekin. Batez beste, egileak izenpetutako hartu-agiria jaso izan denetik artikulua argitaratzeko edo ez argitaratzeko erabakia hartu bitarteko denbora 31 astekoa izan da, baina oso aldakorra da datu hori, artikuluaren luzeraren, gaiaren edo beste zenbait faktoreren arabera.

Artikuluak aztertzeko, itsu bikoitzaren sistema erabili da; hori horrela, egileek ezin izan dute jakin nor izan diren aztertzaileak, eta, beste aldetik, aztertzaileek ere ezin izan dute jakin nor ziren ebaluatzen ari ziren eskui- zkribuen egileak. Horretarako, eskuizkribu guztiak editatu behar izan dira, ebaluatzaile posibleek ez zezaten egilearen/egileen inolako zantzurik aurkitu, ez egileen erreferentziarik, ez testuko deirik (horien ordez "autoaipamena" adierazpena jarri da, diskurtsoa ez hausteko), ez eskerrik eta ez aipamen bibliografikorik. Eragile guztiei (editore gonbidatuak, kanpo-aztertzaileak eta egileak) zehatz-mehatz jakinarazi zaie idatziz zer ebaluazio-mekanismo erabiliko ziren, eta prozesuko fase bakoitzerako jarraibide zehatzak eman zaizkie, baita ebaluatzaileen oharren orientazio-txantiloi bat ere. Ahal izan den neurrian, bitarteko elektronikoen bidez arindu dira eragile guztien arteko harremanak, baina egile bakoitzak bere jatorrizko lanaren hartu-agiri bat izenpetu du, artikulu bakoitzaren goiburuan data jaso delarik, hemen zehazten den protokoloa onartuz horrela.

Artikuluei DOI kodeak eman izanak sarean duten ikusgarritasuna hobetzen du, eta hori nabarmen ari da hobetzen, Google Akademikoaren kontrol-erregistroetan ikus dezakegun eran. 1990etik testu hau idatzi den arte (2017ko abenduaren 29), Munibe Antropologia-Arkeologia aldizkariko (abian 1983az geroztik) artikuluak 4.018 aldiz aipatu dira (joan den urtean 3.554koa zen datua), eta horietatik $1.8402012 a z$ geroztik aipatu dira (duela urtebete, 1.702 ziren). 2012-2016 tartean argitaratutako artikuluak (89 artikulu) 161 aldiz aipatu dira dagoeneko. Datu horrek aldizkariaren azken bost urteotako eragin-faktorea kalkulatzeko aukera ematen digu: 1,81 aipamen argitaratutako artikulu bakoitzeko. Edozein egilek kontsulta dezake aplikazio horren bidez zenbat aldiz aipatu duten bere artikulua, eta zer testuingurutan izan den. Aipatutako azken denbora-tarte horretan, gehien aipatu den artikulua (16 aldiz) honako egile hauek 2012an argitaratutakoa izan da: Ana C. Pinto-Llona, Geoffrey Clark, Panagiotis Karkanas, Bonnie Blackwell, Anne R Skinner, Peter Andrews, Kaye Reed, Alexandra Miller, Rosario Macías-Rosado eta Jarno Vakiparta, "The Sopeña rockshelter, a new site in Asturias (Spain) bearing evidence on the Middle and Early Upper Palaeolithic in Northern Iberia".

Alvaro Arrizabalaga. Editore nagusia

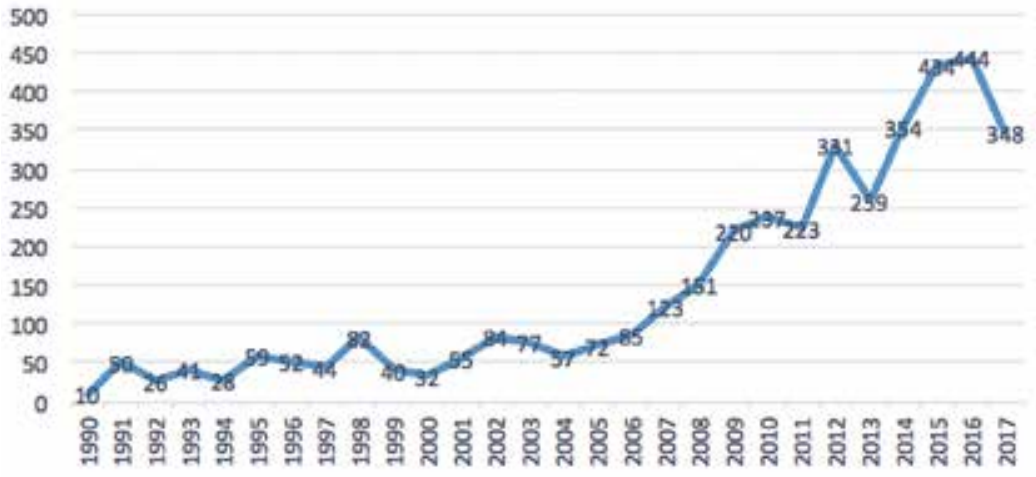

Munibe AA aldizkariaren inguruko aipuak baliabide akademiko ugaritan urte bakoitzean. 


\section{Crónica de la revista Munibe Antropologia-Arkeologia 2017}

En este año 2017, la revista Munibe Antropologia-Arkeologia cumple 69 de andadura, los diez últimos, tras el importante cambio emprendido en su equipo editorial en 2007. La apuesta afrontada por los nuevos formatos y soportes digitales del conocimiento ha permitido a Munibe una progresiva consolidación como cabecera relevante en los ámbitos de la Prehistoria, la Arqueología y la Antropología peninsulares, acompañada de una creciente visibilidad en el ámbito internacional. Año a año, tratamos de incorporar novedades y de actualizar el formato y el contenido de la revista, de modo que resulte más interesante y atractiva para cada vez más autores y de un ámbito más internacional. La novedad principal de este número es la nueva notación bibliográfica (sistema HARVARD, adaptado a los requisitos de la red de revistas ELSEVIER), más homologable con la empleada por diferentes revistas de nuestro campo del conocimiento y que permite recurrir a las aplicaciones habituales de citación, de un modo casi automatizado. Además, la revista ha renovado y amplaido de forma notable su Comité Editorial.

A lo largo de 2017 se han depositado en la redacción de la revista veinte originales para su consideración, que se unen a los cuatro que no pudieron editarse finalmente en la edición en papel de 2016. Debido a circunstancias similares, los últimos dos originales no han podido aún ser evaluados, quedando para su consideración en 2018. Así pues, el total de manuscritos valorados para este número en papel es de veintidós. Cada uno de los originales ha recibido un mínimo de dos revisiones externas, incorporándose en algunos casos una tercera opinión. Cuatro de ellos han sido rechazados por diferentes motivos. Los dieciocho restantes, editados en este número se dividen a partes iguales entre los que han requerido cambios mayores y en los que ha bastado con cambios menores. El periodo medio entre la recepción del acuso de recibo firmado por el autor de correspondencia y la decisión final acerca de la publicación o no del artículo se sitúa en treinta y una semanas, aunque resulta muy variable en función a distintos factores como la longitud o temática del artículo.

El sistema de revisión empleado ha sido nuevamente el de doble ciego, lo que impide, tanto a los autores conocer la identidad de los revisores, como a estos, conocer la de los autores de los manuscritos evaluados. Esto ha obligado a editar cada manuscrito para eliminar cualquier rastro del / de los autores a los eventuales evaluadores: referencias de los autores, llamadas en el texto (sustituidas por la expresión "Autocita", para no romper el discurso), agradecimientos y citas bibliográficas. Todos los agentes (editores invitados, revisores externos y autores) han sido puntualmente informados por escrito de los mecanismos de evaluación que se iban a desarrollar y han dispuesto de instrucciones precisas para cada fase del proceso, incluyendo una plantilla orientativa de indicaciones de los evaluadores. En la medida de lo posible, las relaciones entre todos los agentes se han agilizado por la vía electrónica, aunque cada autor ha firmado un acuse de recibo de su original, con la fecha consignada en la cabecera de cada artículo, aceptando el protocolo aquí detallado.

La dotación de códigos DOI a los artículos viene mejorando su visibilidad en la red, que va mejorando sustancialmente tal y como observamos en los registros de control de Google Académico. Desde el año 1990, hasta la redacción de este texto (29 de diciembre de 2017), los diferentes artículos de Munibe Antropologia-Arkeologia (desde 1983) han sido citados 4018 veces (frente a 3554 veces, el año pasado), 1840 de las cuales desde el año 2012 (por 1702 hace un año). Los artículos publicados durante el periodo 2012-2016 (89 artículos) han sido citados ya 161 veces, lo que nos proporciona el factor de impacto de la revista, para los últimos cinco años, de 1,81 citas por artículo editado. Cualquier autor puede consultar en esta aplicación el número de veces que su artículo ha sido citado y en qué contexto lo ha sido. Para el periodo reciente citado, el artículo más citado (en dieciséis ocasiones) ha sido el publicado en 2012 por Ana C. Pinto-Llona, Geoffrey Clark, Panagiotis Karkanas, Bonnie Blackwell, Anne R Skinner, Peter Andrews, Kaye Reed, Alexandra Miller, Rosario Macías-Rosado y Jarno Vakiparta, "The Sopeña rockshelter, a new site in Asturias (Spain) bearing evidence on the Middle and Early Upper Palaeolithic in Northern Iberia".

\section{Alvaro Arrizabalaga. Editor Principal}

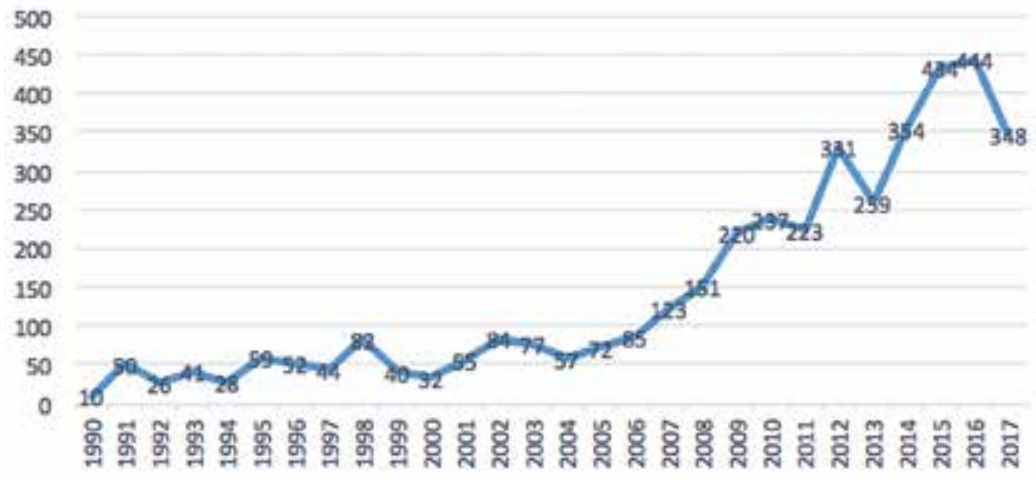

Citas a la revista Munibe AA en distintos medios académicos por año. 